\title{
Prevalence of and risk factors for hallux rigidus: a cross-sectional study in Japan
}

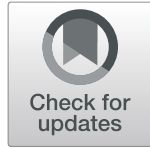

Yoshiyuki Senga', Akinobu Nishimura ${ }^{{ }^{*}}$, Naoya Ito $^{2}$, Yukie Kitaura ${ }^{1}$ and Akihiro Sudo ${ }^{1,3}$

\begin{abstract}
Background: Hallux rigidus (HR) is a common osteoarthritis of the first metatarsophalangeal joint. However, the epidemiology and risk factors of this pathology have yet to be clarified.

Methods: We have been conducting cohort studies among individuals over 50 years old every 2 years since 1997. This study analyzed data from the 7th to 10th checkups in 2009, 2011, 2013, and 2015. We investigated the prevalence of HR and its risk factors in a total of 604 individuals (mean age, $67.1 \pm 6.4$ years; 208 men, 396 women). Radiographic HR was defined as Hattrup and Johnson classification grade 1 or higher. Knee osteoarthritis (KOA) was scored according to the Kellgren-Lawrence grading system. Radiographic KOA was defined as grade 2 or higher. Cases with a hallux valgus (HV) angle of $20^{\circ}$ or higher were defined as showing HV. Statistical analyses were performed using the Kruskal-Wallis test, Fisher's exact test, logistic regression modeling, and the Cochran-Armitage trend test. All $p$-values presented are two-sided and values of $p<.05$ were considered statistically significant.

Results: The prevalence of HR was 26.7\% (161/604). Rates of grade 0, 1, 2, and 3 HR according to the Hattrup and Johnson classification were 73.3\% (443/604), 16.4\% (99/604), 8.0\% (48/604), and 2.3\% (14/604), respectively. Overall ratio of symptomatic HR was $8.1 \%$. Univariate analysis revealed KOA, gout attack (GA), and HV as significantly associated with HR. The same factors were confirmed as independent risk factors for HR in multivariate analysis. All parameters were significantly associated with HR. Odds ratios of KOA, HV, and GA for HR were 1.73, 3.98, and 3.86, respectively. The presence or absence of KOA was significantly associated with severity of HR.
\end{abstract}

Conclusions: This study revealed that the prevalence of HR in the elderly ( $\geq 50$ years) was $26.7 \%$. KOA, HV, and GA were independent risk factors for HR. KOA was associated with severity of HR.

Keywords: Hallux rigidus, Cohort study, Epidemiology

\section{Background}

Hallux rigidus (HR) is an osteoarthritis of the first metatarsophalangeal (MTP) joint, and the most common arthritic condition affecting the foot [1]. HR causes various symptoms, including local pain in the 1st MTP joint, plantar calluses, stiffness, and enlargement of the joint [2]. Radiographically, HR is characterized by joint space narrowing, osteophytic lipping of the metatarsal head and proximal phalanx, and sesamoid hypertrophy [3].

\footnotetext{
* Correspondence: meiten@clin.medic.mie-u.ac.jp

'Departments of Orthopaedic Surgery, Mie University Graduate School of Medicine, 2-174 Edobashi, Tsu city, Mie 514-8507, Japan

Full list of author information is available at the end of the article
}

While arthritis can be caused by traumatic or iatrogenic injuries that directly damage the articular cartilage of the MTP joint, the most common etiology of HR is idiopathic [1].

HR was initially described by Davies-Colley in 1887 [4]. While the pathology is sometimes seen in daily medical practice, its prevalence and epidemiology remain unclear. Previous studies have reported a high prevalence of HR (20-35\%) [5-8], and an extremely high prevalence (61\%) among the population aged over 80 years [7]. However, those studies just examined the prevalence of HR among patients with systematic osteoarthritis. Furthermore, few well-designed studies have investigated

(C) The Author(s). 2021 Open Access This article is licensed under a Creative Commons Attribution 4.0 International License, which permits use, sharing, adaptation, distribution and reproduction in any medium or format, as long as you give appropriate credit to the original author(s) and the source, provide a link to the Creative Commons licence, and indicate if changes were made. The images or other third party material in this article are included in the article's Creative Commons licence, unless indicated otherwise in a credit line to the material. If material is not included in the article's Creative Commons licence and your intended use is not permitted by statutory regulation or exceeds the permitted use, you will need to obtain permission directly from the copyright holder. To view a copy of this licence, visit http://creativecommons.org/licenses/by/4.0/ The Creative Commons Public Domain Dedication waiver (http://creativecommons.org/publicdomain/zero/1.0/) applies to the data made available in this article, unless otherwise stated in a credit line to the data. 
risk factors for $\mathrm{HR}$, although numerous risk factors have been proposed [2]. An in-depth study of HR as diagnosed using the Hattrup and Johnson classification was thus required to clarify the prevalence and risk factors of this entity.

The purpose of this cross-sectional study of a population sample in Japan was to investigate the prevalence of $\mathrm{HR}$ and its risk factors among Japanese community dwellers.

\section{Methods}

\section{Sample collections}

We have been conducting a cross-sectional study among individuals over 50 years old to investigate factors associated with orthopedic-related diseases such as knee osteoarthritis (KOA) and osteoporosis every 2 years since $1997[9,10]$. The present study analyzed individuals recruited from residents of a mountain village in Japan. All investigations were conducted at the local hospital. Before presenting for direct examination, a baseline questionnaire was sent to each participant. Participants answered several questions on age, sex, history of smoking and drinking, foot pain, and medical history, including hypertension, hyperlipidemia, diabetes mellitus (DM), and gout attack (GA). We defined individuals over 65 years old as elderly. In the Research on Osteoarthritis Against Disability study, knee pain was defined as pain occurring in and around the knee joint on most days during the past month, and the same definition was applied in the present study to define foot pain that has continued longer than 1 month [11]. Symptomatic HR was defined as radiographic HR in a patient reporting foot pain. Direct examination consisted of physical measurements of height and weight, a medical interview, a physical examination by an orthopedic surgeon, and Xrays. In the case of X-ray images that could not be evaluated, images were taken again on the spot. Body mass index (BMI) was calculated. Participants also underwent bone mineral densitometry of the forearm to screen for osteoporosis, defined as a bone mineral density $\mathrm{T}$-score of -2.5 or below [12].

\section{Participants}

This study analyzed data from the 7th to 10th checkups, conducted in 2009, 2011, 2013, and 2015, respectively. For those who participated in more than one of these four checkups, only data from the first checkup were included. However, those for whom all screening data were unavailable were excluded. As shown in Fig. 1, 55 of the initial 659 individuals were excluded, leaving a final total of 604 individuals to participate in the study (mean age, $67.1 \pm 6.4$ years; 208 men, 396 women). We divided participants into HR (+) and HR (-) groups according to the presence or absence of HR.

All procedures performed with participants were conducted in accordance with the ethical standards of the institutional and/or national research committee, and with the Declaration of Helsinki (1964) and its later amendments or comparable ethical standards. Written informed consent was obtained from all participants before enrollment.

\section{Definitions of KOA and HR}

Knee X-rays were taken with the patient standing, knee fully extended. KOA was scored according to the Kellgren-Lawrence grading system [13]. Radiographic KOA was defined as grade 2 or higher. We also took foot X-rays with the participant standing upright with both feet on the cassette, as described by Saltzman et al. [14]. Severity of HR was scored based on the modified version of the Hattrup and Johnson classification [15]. Accordingly, severity of HR was classified as: Grade 0, normal; Grade 1, preservation of joint space, mild osteophyte formation; Grade 2, mild to moderate joint space narrowing, moderate osteophyte formation, subchondral sclerosis and cysts; and Grade 3, severe joint space

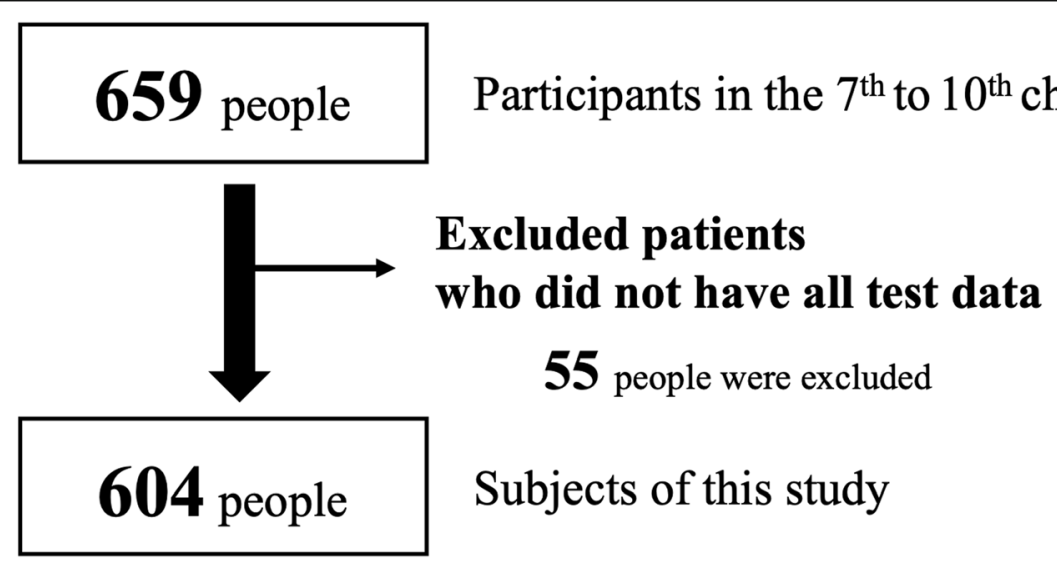

Fig. 1 Flowchart of the selection process for the subjects in this study 
narrowing, significant osteophyte formation, loose bodies, subchondral sclerosis and cysts (Fig. 2). Radiographic HR was defined as grade 1 or higher, with normal appearance classed as grade 0 . Cases with a $\mathrm{HV}$ angle of $20^{\circ}$ or higher were defined as showing HV.

\section{Statistical analysis}

The primary objective of this study was to clarify the prevalence of $\mathrm{HR}$ among individuals who were more than 50 years old. The secondary objective was to explore risk factors for HR. We compared characteristics using the Kruskal-Wallis test for continuous variables and Fisher's exact test for categorical variables. Logistic regression modeling was used to examine the relationship between variables and HR. First, a univariate analysis was performed. Multivariate analysis was then performed by entering those factors showing significant differences in the univariate analysis and adjusting for age and sex. The Cochran-Armitage trend test was used to examine the relationships between risk factors and severity of $H R$ in a linear trend. All statistical analyses were performed using $\mathrm{R}$ version 3.3.2 statistical software ( $\mathrm{R}$ Foundation for Statistical Computing, Vienna, Austria). All $p$-values presented are two-sided and values of $p<.05$ were considered statistically significant.

\section{Results}

\section{Prevalence of HR and participant characteristics}

The prevalence of HR as diagnosed by X-ray examination was $26.7 \%(161 / 604)$ among the entire cohort. Rates of HR grades 0, 1, 2, and 3 were 73.3\% (443/604), $16.4 \%(99 / 604), 8.0 \%(48 / 604)$, and $2.3 \%$ (14/604), respectively. The overall ratio of symptomatic HR was $16.1 \%(26 / 161)$ and the percentage of symptoms did not appear associated with severity of HR (Fig. 3). Table 1 shows a comparison of participant characteristics between groups. No significant differences in various factors were seen between groups, except for KOA, HV, diabetes mellitus, and GA. Specifically, the results showed that patients with KOA, HV, DM, and GA were more likely to have HR.

\section{Risk factors for HRs}

We next examined risk factors for HR. Table 2 shows the results of uni- and multivariate analyses for predictors of HR among the population. Univariate analysis revealed BMI, KOA, $\mathrm{HV}$, diabetes mellitus, and GA as significantly associated with HR. Multivariate analysis confirmed KOA, HV, and GA as independent risk factors for HR (KOA: odds ratio (OR) 1.73, 95\% confidence interval (CI) $0.80-1.85, p<.05$; HV: OR 3.98, 95\%CI 2.68-5.92, $p$ <.05; GA: OR 3.86, 95\%CI 1.24-12.0, $p<$ .05). KOA, HV, and GA thus appear to be independent HR-related factors, suggesting that they may be independent risk factors for HR.

\section{Relationship between KOA and severity of HR}

We subsequently examined whether these risk factors were associated with severity of HR. While HV and GA were not associated with severity of HR, KOA was associated with the severity of HR. Figure 4 shows the relationship between KOA and the severity of HR. KOA is significantly associated with the severity of HR. The frequencies of grades $0,1,2$, and 3 were $23.9 \%$ (106/443), $37.4 \%$ (37/99), 50.0\% (24/48), and 50.0\% (7/14), respectively. The frequency of KOA was significantly associated with the severity of HR $(p<.001)$. Patients with KOA may thus be more likely to have severe HR.

\section{Discussion}

We investigated the prevalence of HR and its risk factors among individuals over 50 years old living in a village in Japan. We identified three important clinical issues: 1) the prevalence of HR among this sample of a general population over 50 years old was $26.7 \%$; 2) KOA, HV,

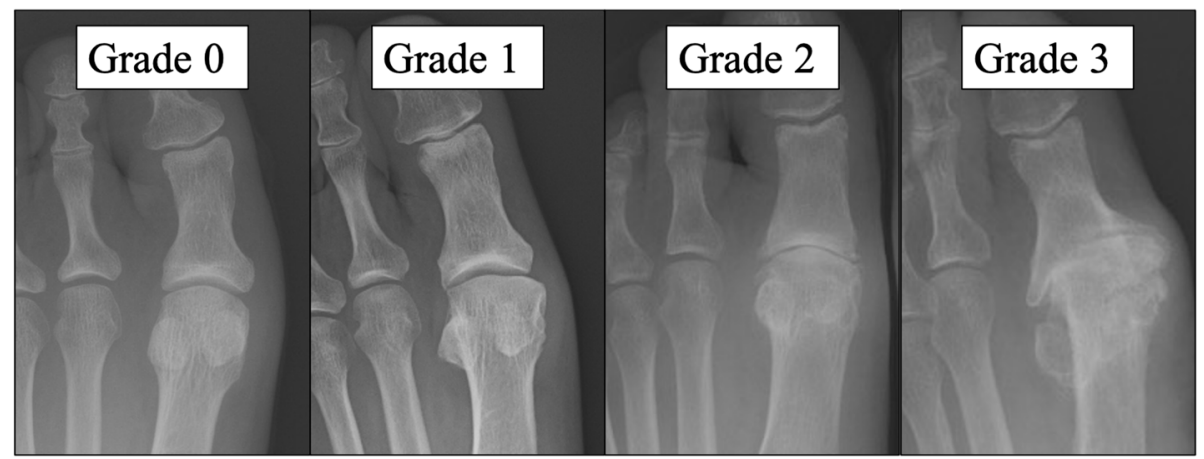

Fig. 2 Severity of hallux rigidus. Grade 0: Normal. Grade 1: Preservation of joint space, mild osteophyte formation. Grade 2: Mild to moderate jointspace narrowing, moderate osteophyte formation, subchondral sclerosis and cysts. Grade 3: Severe joint-space narrowing, significant osteophyte formation, loose bodies, subchondral sclerosis and cysts 


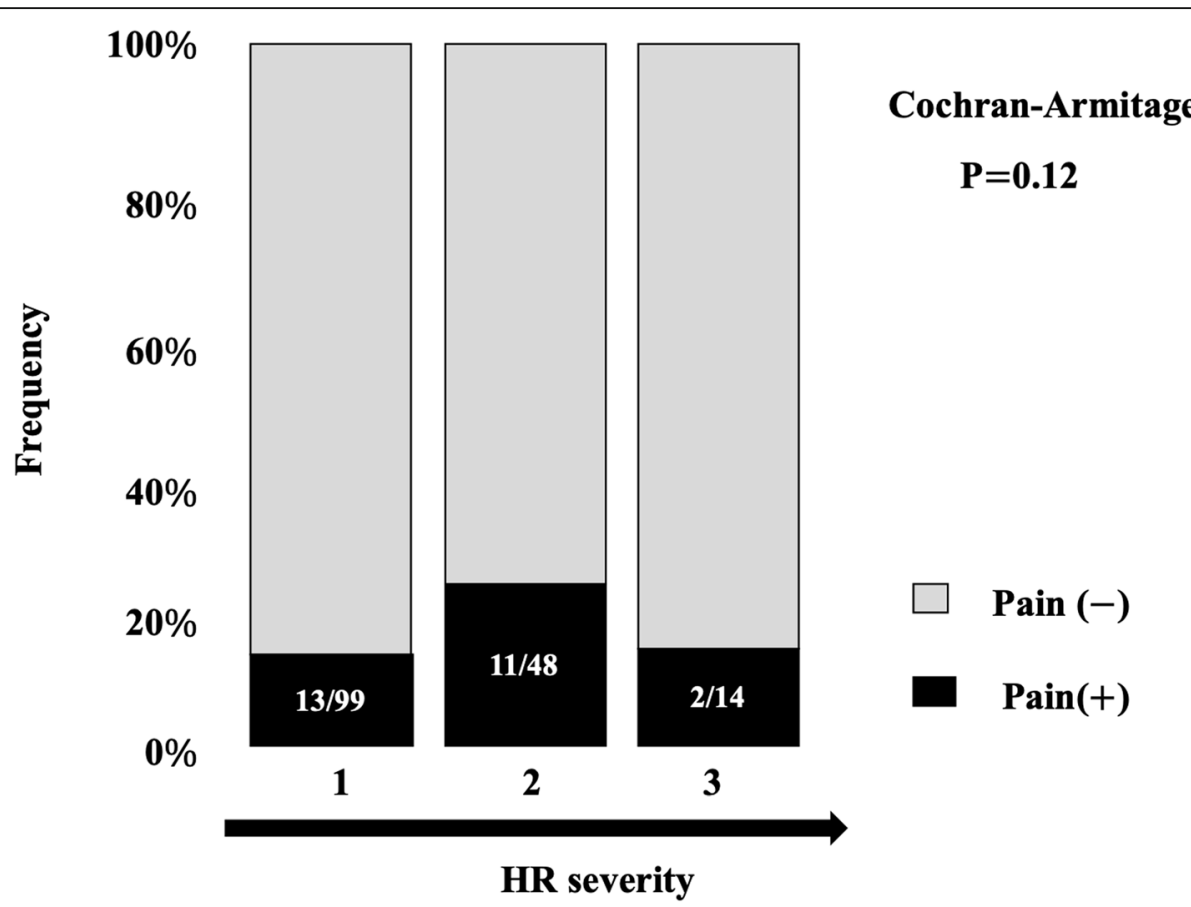

Fig. 3 Ratio of symptomatic hallux rigidus according to severity

and GA were independent risk factors for HR; and 3) KOA was associated with severity of HR.

The $26.7 \%$ prevalence of HR is similar to findings from previous studies (20-35\%) [5-8]. In most such studies, HR was diagnosed using the Kellgren-Lawrence grading system, whereas the present investigation diagnosed HR using the modified Hattrup and Johnson classification. Grade 2 in the Kellgren-Lawrence grading system is almost identical to Grade 1 in the modified Hattrup and Johnson classification. The cut-off criterion for diagnosing HR in this study thus resembled those in previous reports. This is presumably one reason the prevalence of

Table 1 Participant characteristics according to the presence or absence of hallux rigidus

\begin{tabular}{|c|c|c|c|}
\hline Variable & $\begin{array}{l}\text { Hallux rigidus (-) } \\
n=443\end{array}$ & $\begin{array}{l}\text { Hallux rigidus (+) } \\
n=161\end{array}$ & $p$-value \\
\hline Age (mean years $\pm S D$ ) & $66.9 \pm 6.7$ & $67.6 \pm 5.5$ & 0.32 \\
\hline Age $(\geq 65)$ & $326(73.6 \%)$ & $130(80.7 \%)$ & 0.087 \\
\hline Sex (female) & $286(64.6 \%)$ & $110(68.3 \%)$ & 0.44 \\
\hline $\mathrm{BMI}$ & $23.4 \pm 3.3$ & $23.7 \pm 3.1$ & 0.49 \\
\hline $\mathrm{BMI}(\geq 25)$ & $117(26.4 \%)$ & $56(34.8 \%)$ & 0.053 \\
\hline Knee osteoarthritis & $93(21.6 \%)$ & $68(39.1 \%)$ & ${ }^{*}<.001$ \\
\hline Hallux valgus & $100(22.6 \%)$ & $87(54.0 \%)$ & ${ }^{*}<0.01$ \\
\hline Heberden's node & $147(33.2 \%)$ & $64(39.8 \%)$ & 0.24 \\
\hline Vertebral fracture & $62(14.0 \%)$ & $32(19.9 \%)$ & 0.12 \\
\hline Osteoporosis & $106(23.9 \%)$ & $45(28.0 \%)$ & 0.29 \\
\hline Hypertension & $172(38.8 \%)$ & $71(44.1 \%)$ & 0.26 \\
\hline Diabetes mellitus & $33(7.4 \%)$ & $21(13.0 \%)$ & ${ }^{*} 0.037$ \\
\hline Hyperlipidemia & $171(38.6 \%)$ & $57(35.4 \%)$ & 0.51 \\
\hline Gout attack & $8(1.8 \%)$ & $8(5.0 \%)$ & ${ }^{*} 0.044$ \\
\hline Smoking & $78(17.6 \%)$ & $29(18.0 \%)$ & 0.90 \\
\hline Alcohol & $152(34.3 \%)$ & $52(32.3 \%)$ & 0.70 \\
\hline
\end{tabular}

Abbreviations $S D$ standard deviation, $B M I$ body mass index ${ }^{*} p<.05$ 
Table 2 Uni- and multivariate analyses of risk factors for hallux rigidus, adjusted for age and sex

\begin{tabular}{|c|c|c|c|c|}
\hline \multirow[b]{2}{*}{ Variable } & \multicolumn{2}{|l|}{ Univariate } & \multicolumn{2}{|l|}{ Multivariate } \\
\hline & OR $(95 \% \mathrm{Cl})$ & $\overline{p \text {-value }}$ & OR $(95 \% \mathrm{Cl})$ & $p$-value \\
\hline Age $(\geqq 65)$ & $1.51(0.96-2.35)$ & 0.072 & & \\
\hline Sex (female) & $1.18(0.81-1.74)$ & 0.39 & & \\
\hline $\mathrm{BMI}(\geqq 25)$ & $1.49(1.01-2.19)$ & ${ }^{*} 0.045$ & $1.10(0.72-1.70)$ & 0.66 \\
\hline Knee osteoarthritis & $2.32(1.59-3.40)$ & ${ }^{*}<.001$ & $2.08(1.36-3.17)$ & ${ }^{*}<.001$ \\
\hline Hallux valgus & $4.03(2.75-5.91)$ & ${ }^{*}<.001$ & $3.96(2.63-5.96)$ & ${ }^{*}<.001$ \\
\hline Heberden's node & $1.30(0.86-1.97)$ & 0.22 & & \\
\hline Vertebral fracture & $1.49(0.91-2.44)$ & 0.12 & & \\
\hline Osteoporosis & $1.26(0.84-1.89)$ & 0.27 & & \\
\hline Hypertension & $1.24(0.86-1.79)$ & 0.25 & & \\
\hline Diabetes mellitus & $1.86(1.04-3.33)$ & ${ }^{*} 0.036$ & $1.87(0.99-3.52)$ & 0.053 \\
\hline Hyperlipidemia & $0.87(0.59-1.26)$ & 0.45 & & \\
\hline Gout attack & $2.83(1.04-7.67)$ & ${ }^{*} 0.041$ & $3.16(1.05-9.52)$ & ${ }^{*} 0.041$ \\
\hline Smoking & $1.03(0.64-1.65)$ & 0.91 & & \\
\hline Alcohol & $0.91(0.62-1.34)$ & 0.64 & & \\
\hline
\end{tabular}

Abbreviations: $O R$ odds ratio, $C l$ confidence interval, $B M I$ body mass index ${ }^{*} p<.05$

HR in this study was similar to those in previous reports.

Several risk factors have been proposed in the literature, including female sex [16], history of trauma [17], rheumatoid arthritis [18], long proximal phalanx of the hallux [19], varus deformities of the forefoot or rearfoot [19], HV deformity [20], soft-tissue contracture [21], short or long first metatarsal [22], increased interphalangeal angle of the hallux [23], family history [16], and illfitting footwear [24]. However, none of these risk factors were determined from epidemiological studies of local residents. HV, KOA, and GA were identified as independent risk factors in this study. Previous reports have clarified that $\mathrm{KOA}$ is related to $\mathrm{HV}$ [25]. Interestingly, our study demonstrated KOA as an independent risk factor for HR, regardless of HV. Further, the severity of HR was higher in patients with KOA. This may reflect individuals with a genetic predisposition to cartilage damage developing KOA and HR. This possibility is strengthened by a study revealing that OA of the 1st MTP was associated with OA at differing sites, including the knee and interphalangeal joints [8]. In short, we confirmed a close relationship between KOA and HR in the present study. Increased BMI is known to be associated with radiological findings and symptoms of KOA. Similarly in this study, BMI was significantly associated with KOA. However, BMI was not associated with the severity of HR [26].

This study revealed HV as an independent risk factor for HR. HV and HR are two common diseases that affect the 1st MTP joint. Despite affecting the same joint, the clinical and pathological profiles of HV and HR are quite different, and patients are generally accepted to develop either primary HR or HV, not both [27, 28]. However, end-stage HV may be associated with the development of arthritis and may lead to HR.

Mertz reported that the individuals with HR experienced GA more often than those without HR [29]. GA has also been reported to cause inflammation of the 1st MTP joint and erosion of the bone, which may result in HR [30]. Those hypotheses were supported by our study clarifying a history of GA as a strong risk factor for HR.

Several limitations to this study should be considered when interpreting the results. First, this study involved medical checkups in the limited local area of a mountainous, rural area in Japan, and the participants are not representative of the entirety of Japan. Second, this study was cross-sectional in design, and the results thus cannot be used to determine whether risk factors such as KOA cause HR or vice versa. Third, participants were relatively healthy elderly individuals, because they were able to walk to the local hospital. Fourth, we only obtained anteroposterior X-rays of the feet with the participant standing upright; lateral-view images were not taken. Fifth, increased pronation of the hindfoot leads to instability of the first joint, predisposing the joint to degenerative processes, although the presence of flat feet was not considered in this investigation.

\section{Conclusions}

We retrospectively examined the prevalence of $\mathrm{HR}$ and sought to identify associated risk factors among 


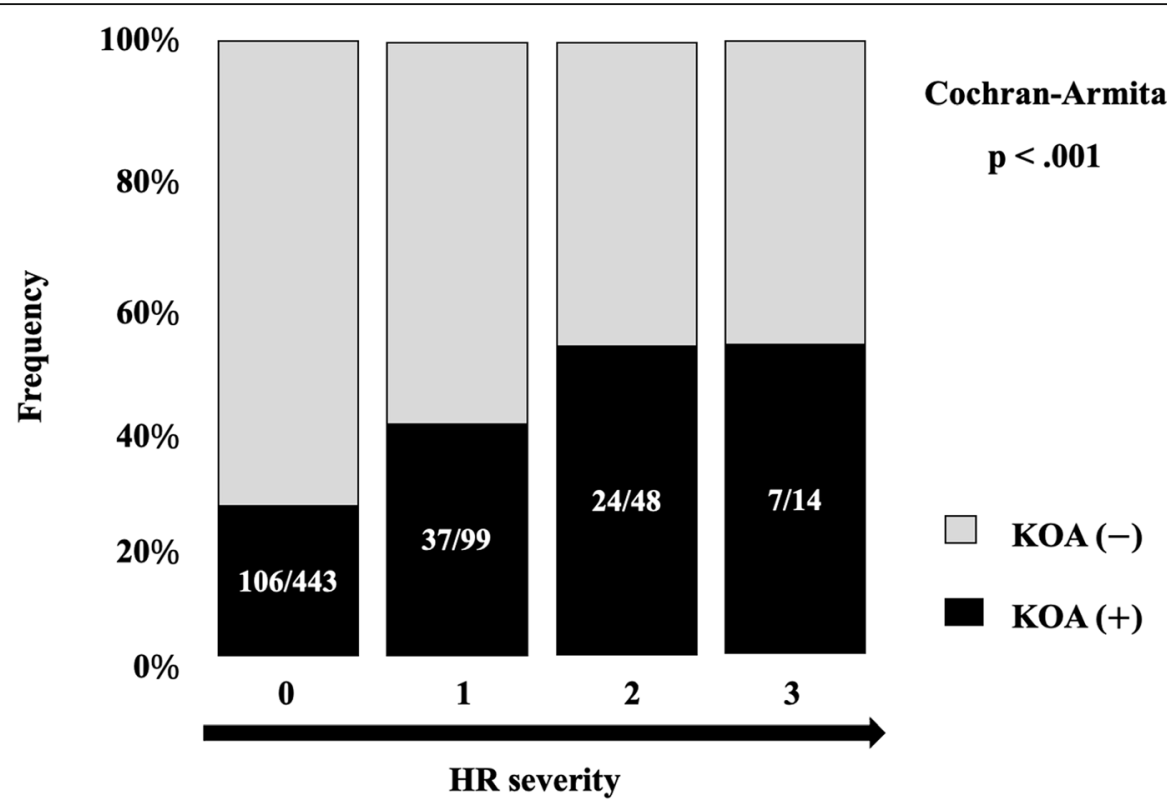

Fig. 4 Relationship between hallux rigidus severity and knee osteoarthritis

individuals over 50 years old. We made three important clinical findings: the prevalence of HR among individuals over 50 years old was $26.7 \%$; KOA, $\mathrm{HV}$, and GA were independent risk factors for $\mathrm{HR}$; and $\mathrm{KOA}$ was associated with the severity of HR. Larger, longitudinal studies are needed to confirm our findings.

\section{Abbreviations}

HR: Hallux rigidus; MTP: Metatarsophalangeal; KOA: Knee osteoarthritis; DM: Diabetes mellitus; GA: Gout attack; HV: Hallux valgus; BMI: Body mass index; OR: Odds ratio; Cl: Confidence interval

\section{Acknowledgements}

The authors wish to thank the medical and nursing staff at Mie University Hospital and Hotoku Clinic.

\section{Authors' contributions}

YS conceived of this study, participated in the study design, performed data acquisition, analysis, and interpretation, and drafted the manuscript. AN conceived of this study, participated in the study design, and helped to draft the manuscript. $\mathrm{NI}$ and YK contributed to the data collection. AS contributed to the study design and coordination. All authors read and approved the final manuscript.

\section{Funding}

This study was supported by JSPS KAKENHI Grant Number JP18K09063.

\section{Availability of data and materials}

The datasets analyzed during the current study are available from the corresponding author on reasonable request.

\section{Declarations}

\section{Ethics approval and consent to participate}

This study was approved by the institutional review board of Mie University Graduate School of Medicine. All participants provided written, informed consent prior to enrolment. All methods were performed in accordance with the relevant guidelines and regulations.
Consent for publication Not applicable.

\section{Competing interests}

The authors declare that they have no competing interests.

\section{Author details}

${ }^{1}$ Departments of Orthopaedic Surgery, Mie University Graduate School of Medicine, 2-174 Edobashi, Tsu city, Mie 514-8507, Japan. ${ }^{2}$ Department of Orthopaedic Surgery, Ise Red Cross Hospital, 1-471-2 Funae, Ise city, Mie 516-8512, Japan. ${ }^{3}$ Department of Orthopaedic and Sports Medicine, Mie University Graduate School of Medicine, 2-174 Edobashi, Tsu city, Mie 514-8507, Japan

Received: 18 May 2021 Accepted: 31 August 2021

Published online: 13 September 2021

References

1. Ho B, Baumhauer J. Hallux rigidus. EFORT Open Rev. 2017;2(1):13-20.

2. Zammit GV, Menz HB, Munteanu SE. Structural factors associated with hallux limitus/rigidus: a systematic review of case control studies. J Orthop Sports Phys Ther. 2009:39(10):733-42.

3. Hanft JR, Mason ET, Landsman AS, Kashuk KB. A new radiographic classification for hallux limitus.J Foot Ankle Surg. 1993:32(4):397-404.

4. Davies-Colley M. Contraction of the first metatarsophalangeal joint of the great toe. Br Med J. 1887;1:728.

5. Bremner JM, Lawrence JS, Miall WE. Degenerative joint disease in a Jamaican rural population. Ann Rheum Dis. 1968:27(4):326-32.

6. Solomon L, Beighton P, Lawrence JS. Osteoarthrosis in a rural south African negro population. Ann Rheum Dis. 1976;35(3):274-8.

7. van Saase $\mathrm{JL}$, van Romunde LK, Cats $\mathrm{A}$, Vandenbroucke JP, Valkenburg HA. Epidemiology of osteoarthritis: Zoetermeer survey. Comparison of radiological osteoarthritis in a Dutch population with that in 10 other populations. Ann Rheum Dis. 1989:48(4):271-80

8. Wilder FV, Barrett JP, Farina EJ. The association of radiographic foot osteoarthritis and radiographic osteoarthritis at other sites. Osteoarthr Cartil. 2005:13(3):211-5.

9. Nishimura A, Akeda K, Kato K, Asanuma K, Yamada T, Uchida A, et al. Osteoporosis, vertebral fractures and mortality in a Japanese rural community. Mod Rheumatol. 2014;24(5):840-3. 
10. Nishimura A, Hasegawa M, Kato K, Yamada T, Uchida A, Sudo A. Risk factors for the incidence and progression of radiographic osteoarthritis of the knee among Japanese. Int Orthop. 2011;35(6):839-43.

11. Muraki S, Oka H, Akune T, Mabuchi A, En-yo Y, Yoshida M, et al. Prevalence of radiographic knee osteoarthritis and its association with knee pain in the elderly of Japanese population-based cohorts: the ROAD study. Osteoarthr Cartil. 2009;17(9):1137-43.

12. Varacallo MA, Fox EJ. Osteoporosis and its complications. Med Clin North Am. 2014;98(4):817-31 xii-xiii

13. Kellgren JH, Lawrence JS. Radiological assessment of osteo-arthrosis. Ann Rheum Dis. 1957;16(4):494-502

14. Saltzman CL, Brandser EA, Berbaum KS, DeGnore L, Holmes JR, Katcherian $\mathrm{DA}$, et al. Reliability of standard foot radiographic measurements. Foot Ankle Int. 1994;15(12):661-5.

15. Hattrup SJ, Johnson KA. Subjective results of hallux rigidus following treatment with cheilectomy. Clin Orthop Relat Res. 1988;226:182-91.

16. Bonney G, Macnab I. Hallux valgus and hallux rigidus; a critical survey of operative results. J Bone Joint Surg (Br). 1952;34-b(3):366-85.

17. Bingold AC, Collins DH. Hallux rigidus. J Bone Joint Surg (Br). 1950;32-b(2): 214-22.

18. Sussman RE, Piccora R. The metatarsal sesamoid articulation and first metatarsophalangeal joint function. J Am Podiatr Med Assoc. 1985;75(6): $327-30$.

19. Camasta CA. Hallux limitus and hallux rigidus. Clinical examination, radiographic findings, and natural history. Clin Podiatr Med Surg. 1996;13(3): 423-48.

20. Lundeen RO, Rose JM. Sliding oblique osteotomy for the treatment of hallux abducto valgus associated with functional hallux limitus. J Foot Ankle Surg. 2000;39(3):161-7.

21. Fuller EA. The windlass mechanism of the foot. A mechanical model to explain pathology. J Am Podiatr Med Assoc. 2000;90(1):35-46.

22. McMurray TP. Treatment of hallux valgus and rigidus. Br Med J. 1936; 2(3943):218-21.

23. Bryant A, Tinley P, Singer K. A comparison of radiographic measurements in normal, hallux valgus, and hallux limitus feet. J Foot Ankle Surg. 2000;39(1): $39-43$.

24. Sim-Fook L, Hodgson AR. A comparison of foot forms among the non-shoe and shoe-wearing Chinese population. J Bone Joint Surg Am. 1958;40-a(5): 1058-62.

25. Nishimura A, Ito N, Nakazora S, Kato K, Ogura T, Sudo A. Does hallux valgus impair physical function? BMC Musculoskelet Disord. 2018;19(1):174.

26. Alahmari KA, Silvian PS, Reddy RS, Ahmad I, Kakaraparthi VN, Alam MM. Mediating role of body mass index in knee osteoarthritis. J Taibah Univ Med Sci. 2017:12(2):150-6.

27. Gilheany MF, Landorf KB, Robinson P. Hallux valgus and hallux rigidus: a comparison of impact on health-related quality of life in patients presenting to foot surgeons in Australia. J Foot Ankle Res. 2008;1 (1):14.

28. Michelson JD, Janowski JW, Charlson MD. Quantitative relationship of first metatarsophalangeal head morphology to hallux rigidus and hallux valgus. Foot Ankle Surg. 2018:24(5):435-9.

29. Mertz DP. Hallux rigidus arthrosis and gout. Fortschr Med. 1982;100(11):446-8.

30. Schlesinger N, Thiele RG. The pathogenesis of bone erosions in gouty arthritis. Ann Rheum Dis. 2010;69(11):1907-12.

\section{Publisher's Note}

Springer Nature remains neutral with regard to jurisdictional claims in published maps and institutional affiliations.

Ready to submit your research? Choose BMC and benefit from:

- fast, convenient online submission

- thorough peer review by experienced researchers in your field

- rapid publication on acceptance

- support for research data, including large and complex data types

- gold Open Access which fosters wider collaboration and increased citations

- maximum visibility for your research: over $100 \mathrm{M}$ website views per year

At $\mathrm{BMC}$, research is always in progress.

Learn more biomedcentral.com/submissions 